\title{
Originals
}

\section{In vitro study of the carry-over effect associated with early diabetic embryopathy in the rat}

\author{
S. Pampfer, Y.D. Wuu, I. Vanderheyden, R. De Hertogh \\ Physiology of Human Reproduction Research Unit, School of Medicine of the University of Louvain, Brussels, Belgium
}

\begin{abstract}
Summary Embryos were recovered from diabetic rats on day 5 of pregnancy and incubated in vitro for up to $72 \mathrm{~h}$. Compared to control embryos, blastocysts from diabetic rats showed a marked impairment in growth that resulted at $48 \mathrm{~h}$ in a higher rate of degeneration and a lower morphological score in the developing population. After $72 \mathrm{~h}$ in vitro, fewer developing blastocysts from diabetic rats formed trophoblastic outgrowths and fewer of those implanted developed an inner cell mass when compared with the control group. When assessed for their cell content, blastocysts from diabetic rats contained fewer cells than control embryos at the start of the culture. This difference persisted, and even worsened, during the ensuing incubation period. The increasing cellular deficiency in blastocysts from diabetic rats was
\end{abstract}

primarily located to their inner cell mass lineage but trophoblast growth was also affected. When trophoblast outgrowths were compared for their surface area and number of nuclei, those collected from diabetic rats were smaller, contained fewer nuclei and had a higher proportion of giant nuclei than control outgrowths. Our data thus demonstrate that despite their removal from the abnormal intra-uterine environment, blastocysts from diabetic rats remain functionally affected by their early exposure and fare less well than control embryos cultured under the same standard conditions. [Diabetologia (1994) 37: 855862]

Key words Blastocyst, trophoblast outgrowth, inner cell mass, carry-over effect, rat.
Extensive clinical studies have confirmed the need to start maternal metabolic treatment before or at the time of conception if the rate of fetal malformations is to be significantly reduced [1-3]. The absolute necessity for periconceptional care is now well accepted, however, the mechanism by which an early exposure to uncontrolled maternal diabetes could be carried-over to the organogenic phase remains to be elucidated [4]. Interesting data pertaining to this issue

Received: 6 December 1993

and in revised form: 22 March 1994

Corresponding author: Professor R. De Hertogh, Physiology of Human Reproduction Research Unit (OBST 5330), School of Medicine of the University of Louvain, 53 Avenue Mounier, B-1200 Brussels, Belgium

Abbreviations: BSA, Bovine serum albumin; TE, trophectoderm; ICM, inner cell mass; TCA, tricholoracetic acid. have been obtained in experiments showing that preimplantation embryos from either drug-treated or spontaneous diabetic mice have a decreased ability to develop in vitro when maintained under the same culture conditions as control embryos $[5,6]$. These observations were made at the morphological level, however, and it is not known whether such a discrepancy in growth potential extends to more subtle differences in the rate of embryonic cell proliferation and differentiation.

In a previous study on the impact of the maternal diabetic condition on preimplantation growth in vivo, we demonstrated that blastocysts collected from diabetic rats contained fewer cells than control embryos [7] and that cells from the lineage responsible for forming the fetus were more affected in their proliferation than the cell population that gives rise to the placenta [8]. This deficiency in preimplantation development was corrected by treating the dia- 
betic pregnant rats with insulin shortly after conception [9]. The present study is an attempt to learn whether preimplantation exposure to maternal diabetes may exert some carry-over effect on the growth of rat embryos following their isolation from the disturbed intra-uterine environment.

\section{Materials and methods}

Reagents. [Methyl- $\left.{ }^{3} \mathrm{H}\right]$-thymidine (cat. TRK758) was supplied by Amersham Int. (Amersham, Bucks., UK). Ham F-10 medium (cat. 07490088), Hanks' balanced salt solution (cat. 04104020), fetal calf serum (cat. 01106290) and fibronectin (cat. 6803010) were from Gibco (Paisley, UK). $\alpha$-D(+)-glucose (cat. G6138) was from Sigma (St. Louis, Mo., USA). Streptozotocin was provided by Upjohn (Kalamazoo, Mich., USA).

\section{Collection of preimplantation embryos}

Sexually mature female Wistar rats were rendered diabetic by administering a single intravenous dose of streptozotocin $(50 \mathrm{mg} / \mathrm{kg})$ [10]. Induction of the diabetic condition was confirmed the next day and only those females with a glycosuria above $2 \%$ were used in subsequent experiments. One or two weeks after the streptozotocin administration, control and diabetic females were mated overnight with males of the same strain and checked the next morning for the presence of a vaginal plug (day 1 of pregnancy). On day 5 of pregnancy, diabetic rats were tested for their blood glucose concentration and those with a glycaemia above $11 \mathrm{mmol} / 1$ were ether anaesthetized. Preimplantation embryos were collected from the uterine horns and immediately transferred onto an inverted phase-contrast microscope [7].

Preimplantation development. Embryos classified as blastocysts were randomized and transferred into Ham F-10 medium supplemented with $6 \mathrm{mmol} / 1$ glucose, $1 \mathrm{mmol} / \mathrm{l} \mathrm{L}$-glutamine, $1 \mathrm{~g} / 1 \mathrm{BSA}$ and antibiotics [7] in a humidified atmosphere $\left(5 \% \mathrm{CO}_{2}\right.$ in air) at $37^{\circ} \mathrm{C}$. At the beginning of the incubation period and after 24 or $48 \mathrm{~h}$ in culture medium with $1 \mathrm{~g} / \mathrm{l}$ BSA, blastocysts were examined for stage of development and number of cells. Development was assessed on an inverted microscope and the average morphological score was calculated according to the following developmental scale: nascent blastocoele $=7$, clearly demarcated trophectoderm (TE) and inner cell mass $(\mathrm{ICM})=8$, expanded blastocoele $=9$, hatching from the zona pellucida $=10$ and fully-hatched blastocyst $=11$ [11]. The number of nuclei was determined on a fluorescence microscope after blastocysts were processed through a dual staining method that allows for the separate counting of the two embryonic cell lineages present at that stage: the TE and the ICM [12]. The number of nuclei in a preimplantation blastocyst was assumed to correspond to its number of cells [12].

Peri-implantation development. In order to compare their capacity to implant in vitro, blastocysts from control and diabetic rats were also cultured according to another protocol for a total of $72 \mathrm{~h}$. Blastocysts were recovered as stated and cultured for a $36-\mathrm{h}$ period in Ham F-10 medium supplemented as stated except that $10 \%$ fetal calf serum was substituted for
BSA. The embryos were then transferred into fibronectincoated culture wells [13] for an additional 36-h period in Ham F-10 complemented with $4 \mathrm{~g} / \mathrm{l}$ BSA. Under these conditions, blastocysts attach to the bottom of the culture wells and begin to spread out over the fibronectin-coated substrate. Embryos were examined after the first incubation phase, thus at the time of their transfer into coated wells $(36 \mathrm{~h})$, and at the end of the experiment $(72 \mathrm{~h})$. At $72 \mathrm{~h}$, normal outgrowths appear as composed of a central ICM cluster surrounded by a monolayer of flat trophoblastic cells [14]. Control and diabetic outgrowths were assessed at that time according to different parameters. Their morphology was evaluated on an inverted microscope as a function of the size and aspect of the ICM, ranging from +++ (enlarged compact mass) to + (few scattered cells). Overall proliferation of the outgrowths was estimated by weighing cut-out images of implanted embryos [15] and by assessing their rate of DNA synthesis activity [16]. DNA synthesis was measured by pulsing the embryos for $4 \mathrm{~h}$ in Ham F-10 medium containing $\left[{ }^{3} \mathrm{H}\right]$-thymidine (final specific activity was $6 \mathrm{Ci} / \mathrm{mmol}$ ) and $4 \mathrm{~g} / 1 \mathrm{BSA}$. After repeated washings in the presence of a 1000-fold excess of unlabelled thymidine, the embryos were solubilized in $300 \mu 1 \mathrm{H}_{2} \mathrm{O}$ containing $1 \mathrm{~g} / 1 \mathrm{BSA}$ as carrier and precipitated with an equal volume of $10 \%$ TCA. Amounts of radioactive isotope were counted separately in the TCA-soluble and TCA-insoluble fractions of the blastocyst extracts.

Outgrowths at $72 \mathrm{~h}$ were also prepared for the direct counting of their number of nuclei by means of a staining technique previously used on preimplantation embryos [7] and modified in this study to investigate trophoblast outgrowths. At the end of the incubation period, the culture medium was carefully removed from the culture wells and replaced with $50 \mu \mathrm{l}$ of $0.9 \%$ hypotonic sodium citrate for $10 \mathrm{~min}$. This solution was evaporated under vacuum at $37^{\circ} \mathrm{C}$ for $30 \mathrm{~min}$ and replaced with $50 \mu \mathrm{l}$ of ethanol: acetic acid (3:1). The fixative was then evaporated under partial vacuum (200 torr) for 60-90 min. Dried embryos were stained with $50 \mu \mathrm{l}$ of $40 \mu \mathrm{mol} / \mathrm{l}$ propidium iodide for $30 \mathrm{~min}$ in the dark. Following nuclear counting on a fluorescence microscope, the preparations were restained with a $4 \%$ Giemsa solution and re-examined under visible light. The same preparations were also examined for the presence of giant nuclei. In preliminary experiments, 366 nuclei from control outgrowths were measured for their surface area and their distribution analysis showed two peaks at $51.97 \pm 18.85 \mu \mathrm{m}^{2}$ and 206.43 $\pm 32.69 \mu^{2}$ (means $\pm S E M$ ). These peaks were considered as representing diploid and tetraploid nuclei based on the relationship previously described in murine trophoblast outgrowths between nuclear area and DNA content [17]. Nuclei with a surface area greater than $240 \mu \mathrm{m}^{2}$ were therefore counted as giant polyploid nuclei.

\section{Statistical analysis}

Statistical differences between control and diabetic mean values were usually analysed by unpaired two-tailed Student's $t$-test but one-way analysis of variance was performed when appropriate, as indicated in the text. Statistical differences between control and diabetic distribution patterns were tested by chi-square analysis. 
Table 1. Recovery of rat blastocysts on day 5 of pregnancy

\begin{tabular}{lll}
\hline & Control rats & Diabetic rats \\
\hline Number of rats & 116 & 131 \\
Glycaemia (mmol/1) & $5.92 \pm 0.14$ & $25.38 \pm 0.46^{\mathrm{a}}$ \\
Number of embryos per rat & $8.97 \pm 0.15$ & $7.97 \pm 0.17^{\mathrm{a}}$ \\
Number of structures per rat & & \\
- Blastocysts & $6.46 \pm 0.22$ & $4.84 \pm 0.24^{\mathrm{a}}$ \\
- Morulae & $2.11 \pm 0.17$ & $1.93 \pm 0.16$ \\
- Others & $0.42 \pm 0.09$ & $1.22 \pm 0.16^{\mathrm{a}}$ \\
\hline
\end{tabular}

Results are given as means \pm SEM

${ }^{\mathrm{a}} p<0.01$ between control and diabetic values

Table 2. Morphological development of control and diabetic rat blastocysts

\begin{tabular}{lll}
\hline Culture time & \multicolumn{2}{c}{ Average morphological score per embryo } \\
\cline { 2 - 3 } & Control blastocysts & Diabetic blastocysts \\
\hline Start & $8.00 \pm 0.04$ & $7.97 \pm 0.02$ \\
$n$ & 151 & 172 \\
$24 \mathrm{~h}$ & $9.02 \pm 0.09$ & $8.86 \pm 0.09$ \\
$n$ & 56 & 59 \\
$48 \mathrm{~h}$ & $10.24 \pm 0.12$ & $9.65 \pm 0.11^{\mathrm{a}}$ \\
$n$ & 61 & 68 \\
\hline
\end{tabular}

Results are given as means \pm SEM.

$n$ is the number of embryos in each group.

${ }^{a} p<0.01$ between control and diabetic values.

See Materials and Methods for a description of the developmental scale

\section{Results}

\section{Morphological development}

Embryos were recovered from control and diabetic rats on day 5 of pregnancy and classified according to their morphology. In accordance with previous observations $[7,8]$ diabetic rats produced fewer embryos than control rats $(p<0.01)$ and a smaller proportion $(60 \%$ vs $72 \%)$ of these embryos had reached the blastocyst stage at collection time (Table 1). Only those embryos showing the regular features of healthy blastocysts (an outer monolayer of trophoblast cells surrounding the blastocoele cavity and an eccentered ICM) were selected for further growth in vitro. Due to this initial selection, blastocysts from control and diabetic rats had very close mean morphological scores at the beginning of the culture experiments, with most of them at developmental stage 8 (Table 2). After $24 \mathrm{~h}$ in culture medium with $1 \mathrm{~g} / 1 \mathrm{BSA}$, about $12 \%$ of the control blastocysts and $22 \%$ of the diabetic blastocysts showed severe signs of degeneration. Most degenerating embryos showed a collapsed blastocoele and/or blastomeres of unequal sizes as well as evidence of cytoplasmic fragmentation. During this time interval, developing embryos expanded by enlargement of their blastocoele, and no statistical difference was detect-
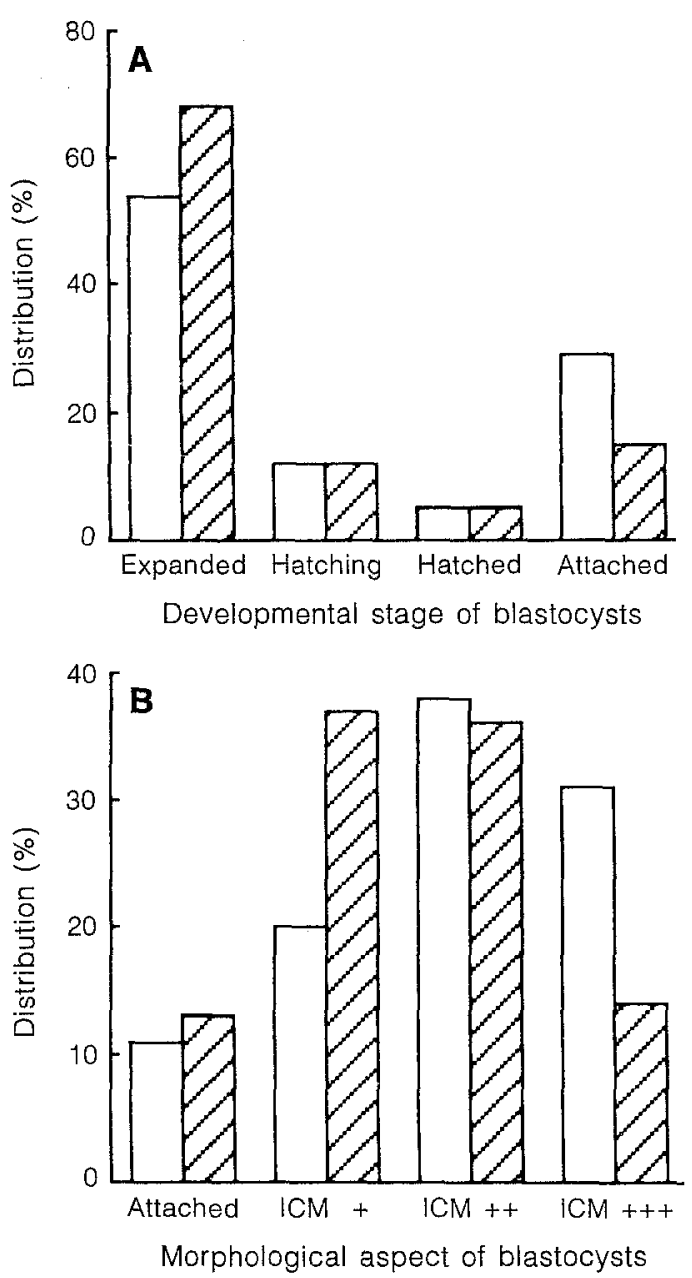

Fig. 1. (A, B) Distribution of blastocysts from control and diabetic rats as a function of their morphology. Embryos from control $(\square)$ or diabetic (प) rats were cultured in vitro and examined after $36 \mathrm{~h}(\mathbf{A})$ or $72 \mathrm{~h}(\mathbf{B})$. At $36 \mathrm{~h}$, those embryos which had continued their development were classified as expanded, hatching from the zona pellucida, fully hatched or attached blastocyst. At $72 \mathrm{~h}$, developing embryos were classified as attached or outgrown and the aspect of their ICM was graded from +++ (compact aggregate of rounded cells) to + (a few scattered cells over the trophoblastic layer). Degenerating embryos were discarded from the counting. Differences between control and diabetic distributions (\%) were statistically significant at $36 \mathrm{~h}(p<0.05)$ and $72 \mathrm{~h}(p<0.01)$ by chi-square analysis

ed in the average morphological score attained by advancing control and diabetic blastocysts (Table 2). During a second $24-\mathrm{h}$ period in culture medium with $1 \mathrm{~g} / \mathrm{l} \mathrm{BSA}$, an additional $13 \%$ of control blastocysts and $16 \%$ of diabetic blastocysts interrupted their development and displayed degenerative features. Advancing embryos proceeded through the hatching phase but those from diabetic rats were found to progress at a lower rate than control blastocysts $(p<$ 0.01) (Table 2).

A similar difference was observed when embryos were recovered from control or diabetic rats on day 5 of pregnancy and incubated for $36 \mathrm{~h}$ in a culture 

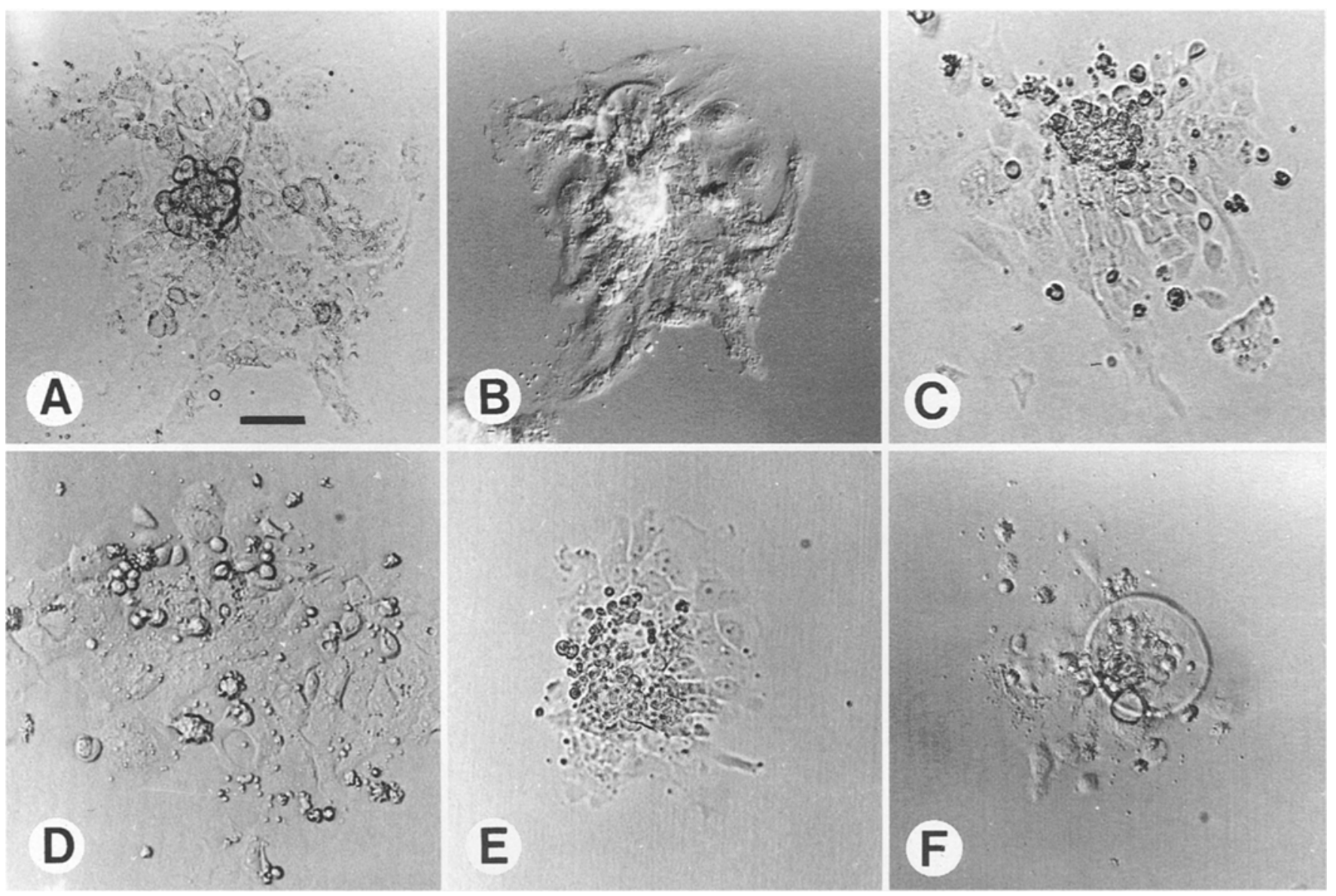

Fig.2. (A-F) Rat trophoblast outgrowths at $72 \mathrm{~h}$. (A) Control embryo spread over the substrate and containing a monolayer of TE cells and a compact cluster of ICM cells. (B) Same embryo examined with Nomarski contrast optics. (C) Diabetic embryo with normal TE and ICM (+++) populations. (D) Diabetic embryo with a normal layer of TE cells and only a few ICM cells ( + ). (E) Diabetic embryo with limited trophoblast outgrowth. (F) Diabetic embryo partially encased in its zona pellucida and attached to the substrate. The scale bar represents $50 \mu \mathrm{m}$ except for $(\mathbf{B})$ where it represents $60 \mu \mathrm{m}$

medium supplemented with fetal calf serum instead of BSA. Although the addition of fetal calf serum to the culture medium accelerated the overall rate of embryo development, diabetic blastocysts remained markedly delayed in their progression compared to control blastocysts $(p<0.05)$ (Fig. 1A). This difference increased further following the transfer of the blastocysts from the first culture phase with fetal calf serum into fibronectin-coated wells filled with culture medium with $4 \mathrm{~g} / \mathrm{l}$ BSA for another $36 \mathrm{~h}$ (Fig.1B). During this second time interval, trophoblast cells begin to extend around the site of embryo attachment and form an epithelial-like monolayer while the ICM remains as a protubing aggregate of compacted cells (Fig.2). At the end of the experiment, thus after a total of $72 \mathrm{~h}$ in vitro, about $12 \%$ of the control blastocysts and $24 \%$ of the diabetic blastocysts had interrupted their development. In both culture groups, approximately $10 \%$ of the blastocysts showed adherence to the substrate but failed to develop beyond a limited outgrowth (Fig.2). Among progressing embryos, $36 \%$ of the control embryos and only $16 \%$ of the diabetic embryos displayed a compact ICM above a large trophoblast outgrowth. The proportion of outgrowths with scattered ICM cells or no ICM at all was markedly higher in the diabetic group than in the control group $(p<0.01)$ (Fig. 1B).

\section{Cell proliferation}

Although blastocysts selected from control and diabetic rats were morphologically equivalent at the start of the culture, those from the diabetic group contained fewer cells than control embryos ( $p<$ 0.05 ) (Table 3). As reported previously [8], this decrease in cellular proliferation was more pronounced in the ICM lineage, where the deficiency amounted to $11 \%$ of the corresponding control value, than in the TE. After $24 \mathrm{~h}$ in culture medium with $1 \mathrm{~g} / 1$ BSA, the total number of cells was still lower in diabetic blastocysts than in control blastocysts, despite the fact that degenerating embryos had been dis- 
Table 3. Cell proliferation in control and diabetic rat blastocysts

\begin{tabular}{llll}
\hline $\begin{array}{l}\text { Culture } \\
\text { time }\end{array}$ & Cell lineage & \multicolumn{2}{c}{ Average cell number per embryo } \\
\cline { 3 - 4 } & & $\begin{array}{l}\text { Control } \\
\text { blastocysts }\end{array}$ & $\begin{array}{l}\text { Diabetic } \\
\text { blastocysts }\end{array}$ \\
\hline Start & ICM & $11.97 \pm 0.39$ & $10.63 \pm 0.53^{\mathrm{a}}$ \\
& TE & $23.59 \pm 0.76$ & $21.63 \pm 0.71$ \\
& TOT & $35.56 \pm 1.04$ & $32.26 \pm 1.03^{\mathrm{a}}$ \\
& $n$ & 37 & 38 \\
$24 \mathrm{~h}$ & ICM & $13.63 \pm 0.30$ & $10.74 \pm 0.31^{\mathrm{b}}$ \\
& TE & $35.71 \pm 1.16$ & $32.68 \pm 1.02^{\mathrm{a}}$ \\
& TOT & $49.34 \pm 1.39$ & $43.42 \pm 1.18^{\mathrm{b}}$ \\
& $n$ & 56 & 59 \\
$48 \mathrm{~h}$ & ICM & $18.12 \pm 0.57$ & $13.45 \pm 0.53^{\mathrm{b}}$ \\
& TE & $59.34 \pm 1.21$ & $55.38 \pm 1.41^{\mathrm{b}}$ \\
& TOT & $77.46 \pm 1.68$ & $68.83 \pm 1.70^{\mathrm{b}}$ \\
& $n$ & 50 & 53 \\
\hline
\end{tabular}

$\mathrm{TOT}=\mathrm{ICM}+\mathrm{TE}$

Results are given as means \pm SEM

$n$ is the number of embryos in each group.

${ }^{\mathrm{a}} p<0.05$ and ${ }^{\mathrm{b}}<0.01$ between control and diabetic values

Table 4. Developmental parameters in implanted rat blastocysts at $72 \mathrm{~h}$

\begin{tabular}{lcc}
\hline & $\begin{array}{l}\text { Control } \\
\text { blastocysts }\end{array}$ & $\begin{array}{l}\text { Diabetic } \\
\text { blastocysts }\end{array}$ \\
\hline $\begin{array}{l}\text { Surface area per } \\
\text { outgrowth }\left(\mu \mathrm{m}^{2}\right)\end{array}$ & $46301.97 \pm 1702.65$ & $40138.61 \pm 2017.16^{\mathrm{a}}$ \\
$n$ & 77 & 66 \\
$\begin{array}{l}\text { Number of nuclei } \\
\text { per outgrowth }\end{array}$ & $100.44 \pm 3.58$ & $89.61 \pm 2.79^{\mathrm{a}}$ \\
$n$ & 54 & 52 \\
$\begin{array}{l}\text { Number of giant nuclei } \\
\text { per outgrowth }\end{array}$ & $4.61 \pm 0.44$ & $5.69 \pm 0.50$ \\
$\begin{array}{l}\text { Proportion of giant nuclei } \\
\text { per outgrowth (\%) }\end{array}$ & $5.02 \pm 0.53$ & $6.72 \pm 0.63^{\mathrm{a}}$ \\
$n$ & 54 & 52 \\
$\begin{array}{l}\text { DNA synthesis activity } \\
\text { (dpm per outgrowth) }\end{array}$ & & \\
$\begin{array}{l}\text { Thymidine uptake } \\
\text { Thymidine incorporation }\end{array}$ & $130.59 \pm 18.70$ & $175.12 \pm 25.58$ \\
$n$ & 17 & 18 \\
\hline
\end{tabular}

Results are given as means \pm SEM

$n$ is the number of outgrowths in each group except for DNA synthesis where it represents the number of batches in each group.

${ }^{a} p<0.05$ between control and diabetic values

carded from the cell counting $(p<0.01)$. The cell deficiency in the ICM was more accentuated after $24 \mathrm{~h}$ than it was at the start of the culture period since the mean ICM cell number in diabetic blastocysts after culture was $21 \%$ lower than the control value (Table 3 ). In contrast, the difference in the TE lineage remained at about $8 \%$. When the incubation was proceeded for a total of $48 \mathrm{~h}$ in culture medium with $1 \mathrm{~g} / 1$ BSA, blastocysts from the diabetic group continued to contain fewer cells than the control embryos $(p<$ 0.01 ) (Table 3 ) and, as a consequence, their total cell number distribution was clearly displaced toward the

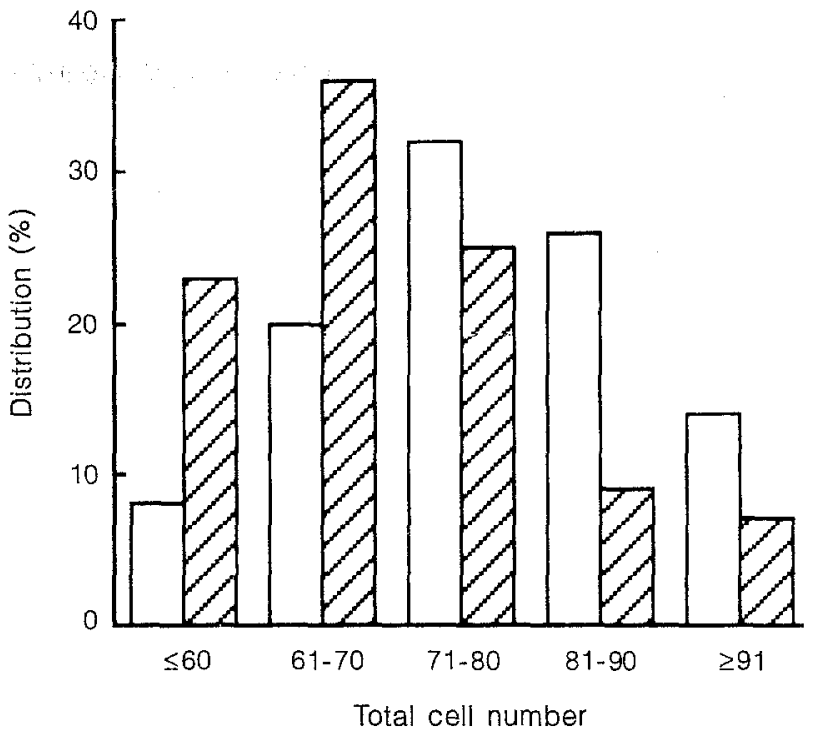

Fig. 3. Distribution of blastocysts from control and diabetic rats as a function of their total cell number. Embryos from control $(\square)$ or diabetic $(\square)$ rats were cultured for $48 \mathrm{~h}$ in vitro and counted for their total number of cells. Blastocysts from diabetic rats showed a delay in their cell proliferation rate that translated into a shift of their cell number distribution to the left. The difference between control and diabetic distributions $(\%)$ was statistically significant $(p<0.05)$ by chi-square analysis

lower range (Fig.3). The relative deficiency in ICM cells continued to increase from 24 to $48 \mathrm{~h}$ and the average ICM cell number obtained in diabetic blastocysts at the end of the 48 -h period was $26 \%$ lower than the corresponding control value. The difference in the TE lineage was close to $7 \%$.

According to our second culture protocol, embryos from control or diabetic rats were incubated in culture medium with FCS for $36 \mathrm{~h}$ and then transferred into fibronectin-coated wells filled with culture medium with $4 \mathrm{~g} / \mathrm{l} \mathrm{BSA}$ for another $36 \mathrm{~h}$. A limited number of blastocysts was analysed at the end of the first incubation phase for their total cell number. Despite the presence of fetal calf serum in the medium, diabetic blastocysts continued to display a significant deficiency in cell proliferation as they were found to contain fewer cells than control embryos $(83.84 \pm 2.21$ vs $90.50 \pm 1.84$ cells in 18 diabetic and 17 control embryos, respectively, $p \leq 0.05$ ). Following their transfer and incubation for a total of $72 \mathrm{~h}$ in vitro, trophoblast outgrowths derived from diabetic blastocysts showed a smaller surface value compared with control embryos $(p<0.05)$ (Table 4$)$. This decrease in development was confirmed when trophoblast outgrowths were stained with a fluorescent DNA dye and counted for their total number of nuclei (Fig.4). Even when attached embryos with limited spreading and development were discarded from the scoring, outgrowths from diabetic blastocysts contained on average $11 \%$ fewer nuclei than 
860
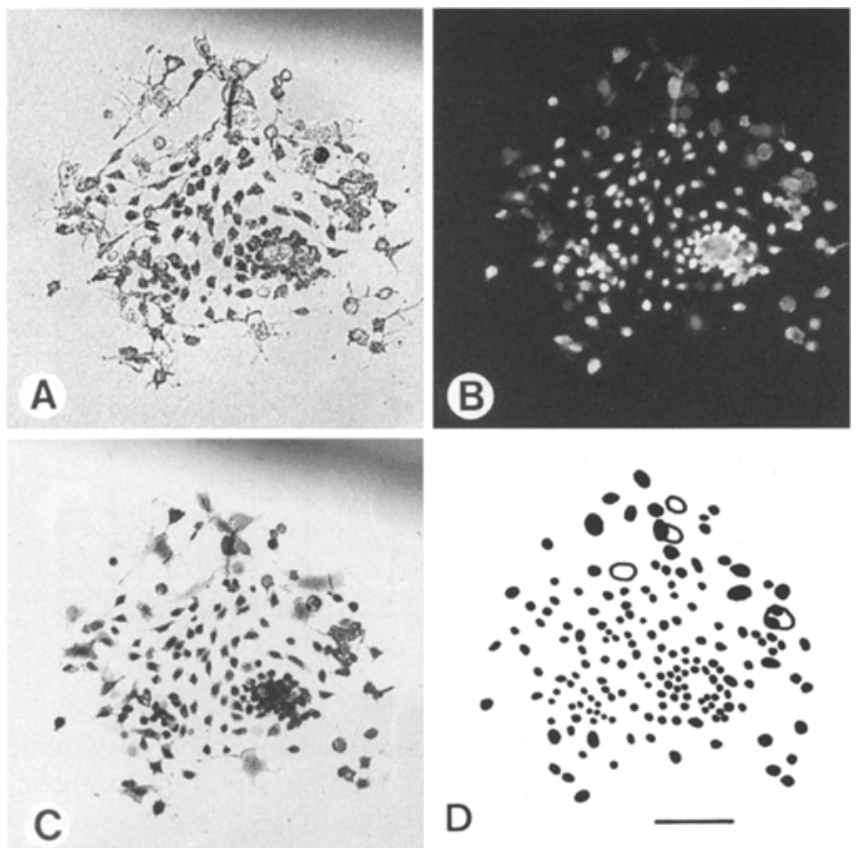

Fig. 4A-D. Nuclear staining of trophoblast outgrowths. (A) Control embryo at $72 \mathrm{~h}$. (B) Same embryo after fixation and staining with propidium iodide under fluorescent light and (C) after restaining with Giemsa under visible light. (D) Drawning of the embryo on paper to count the total number of nuclei (163 nuclei). Open circles in $(\mathbf{D})$ represent staining spots that were not identified as nuclei. The scale bar represents $50 \mu \mathrm{m}$

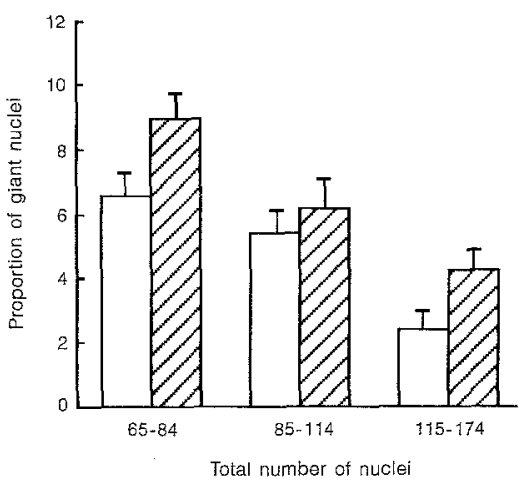

Fig.5. Average proportion of giant nuclei in trophoblast outgrowths. Embryos from control $((\square)$ or diabetic $((\square)$ rats were cultured for $72 \mathrm{~h}$ in vitro and counted individually for their total number of nuclei and their proportion of giant nuclei. Embryos were then grouped in different categories according to their nuclear number and the average proportion of giant nuclei was calculated in each group. Diabetic and control embryos in the low total nuclear number range contained proportionally more giant nuclei than larger outgrowths $(p<$ 0.05 by one-way analysis of variance). In each group, diabetic embryos contained more giant nuclei than corresponding control embryos. Results are given as means \pm SEM

control embryos $(p<0.05)$ (Table 4$)$. In addition, diabetic outgrowths showed an increase in the proportion of giant nuclei $(p<0.05)$ (Table 4$)$. In both diabetic and control groups, embryos with a low total nuclear number contained relatively more giant nuclei
S. Pampfer et al.: In vitro growth of embryos from diabetic rats

than larger outgrowths $(p<0.05)$ (Fig. 5). In order to investigate whether the difference in total nuclear number was associated with a decrease in DNA synthesis, batches of 2 to 5 trophoblast outgrowths were incubated for $4 \mathrm{~h}$ in the presence of $\left[{ }^{3} \mathrm{H}\right]$-thymidine and assessed for the utilization of this radioactive precursor. Both the incorporation rate and the total uptake rate of radioactive thymidine were increased in diabetic outgrowths compared with control embryos but the differences between the two groups were not statistically significant (Table 4).

\section{Discussion}

In pregnant diabetic rats, induction of transient phases of metabolic disturbance before and around the time of implantation have been previously shown to increase the rates of fetal resorptions and malformations compared with offspring from non-diabetic rats $[18,19]$. In streptozotocin- or alloxan-treated diabetic mice, embryos collected at the one-cell stage and maintained in vitro in parallel with control embryos have been reported to be markedly diminished in their developmental rate [5]. A similar pattern of growth impairment in vitro was reported when embryos obtained from diabetic non-obese diabetic mice at the blastocyst stage were compared with non-diabetic controls [6]. All these studies pointed toward the possibility that intra-uterine exposure to faulty maternal metabolism during the very early days of development could have long-lasting effects on the growth potential of the embryos. We have now provided evidence that blastocysts from day 5 pregnant diabetic rats have a decreased growth potential in vitro compared to control embryos.

Our data demonstrate that embryos from diabetic rats not only progressed at a slower pace through blastocyst maturation and implantation but that they also persistently contained fewer cells than control embryos. This difference was still detected after degenerated embryos, present in higher proportion in the diabetic group, had been discarded before cell counting. Moreover, the deficiency in cell proliferation seemed preferentially located in the ICM of the blastocysts and tended to worsen as the incubation time increased. The relative size of the ICM population decreased in diabetic blastocysts throughout the culture period and a larger proportion of these embryos failed to maintain a compact aggregate ICM following attachment to the substrate by the time the experiment was complete. The data therefore suggest that although embryos exposed to maternal diabetes were capable of initial differentiation into ICM and TE, the development potential of the ICM lineage was severely diminished. This deficiency might prove crucial later in pregnancy since ICM derivatives serve as a unique stem cell source for all 
the different layers of the fetus. Although affected to a lesser degree, trophoblast cells were not completely protected from the deleterious influence of maternal diabetes, as the integrity of the TE layer surrounding the implanted embryos appeared to be altered in the diabetic group at the end of the culture period.

The mechanism of the peri-implantation developmental deficiency associated with maternal diabetes will be difficult to identify as it may reflect a large variety of both direct and indirect effects. Our results indicate that neither the rate of DNA synthesis after $72 \mathrm{~h}$ in vitro (this study) nor the level of glucose consumption at retrieval time [20] were significantly altered in blastocysts from diabetic rats. In addition, data from a preliminary investigation of the rate of protein synthesis pointed to the absence of difference between blastocysts from diabetic and control rats at recovery time (unpublished results). It is therefore possible that the origin(s) of the carry-over effect reported here will have to be investigated at a more subtle level. Previous observations have shown, for instance, that the expression pattern of the fibronectin gene was altered in tissues of diabetic rats in a long-lasting fashion that persisted for weeks after restoration of normal glycaemia [21]. The fact that substantial divergences are initiated at the gene expression level between ICM and TE cells when the two cell lineages begin to form at the blastocyst stage [22] together with the difference between ICM and TE in terms of carry-over deficiency are indicative of a role for specific gene alterations in the proliferation and differentiation dysfunctional pattern associated with early diabetic embryopathy. Earlier studies have shown that ICM cells control TE proliferation by preventing or limiting TE transformation into giant cells [23]. In the presence of impaired ICM cells, as is apparently the case in diabetic blastocysts, TE cells might engage in an uncontrolled process of transformation and disturb the structure of the implanting embryo. This would explain the increased proportion of giant nuclei in outgrowths from diabetic rats and the slight increase in DNA synthesis activity measured in these implants.

The question of whether administration of insulin to diabetic rats would abolish the carry-over effect harboured by preimplantation embryos has not been addressed in the present work. Our previous observations have shown, however, that the partitioning of ICM and TE cells in blastocysts was normalized by insulin treatment [9]. Administration of insulin to drug-treated and spontaneous diabetic mice also restored normal viability in preimplantation embryos recovered from the reproductive tract and cultured in vitro for several days [5, 6]. In summary, our study demonstrates that the developmental deficiency observed in day 5 blastocysts from diabetic rats tends to persist, and even worsen, after the embryos have been removed from the deleterious intra-uterine environment and transferred into culture conditions that support the development of control embryos. Owing to the vital role played by the ICM lineage in organogenesis, it is therefore possible that this carry-over effect may add to the combination of various complex factors causing developmental abnormalities during diabetic pregnancy. More experiments will have to be done before a firmer link between preimplantation growth alteration and fetal malformations can be established.

Acknowledgements. This research was financed by grants from the Juvenile Diabetes Foundation International, and from the Fund for Medical Scientific Research (Belgium), the Fund for Scientific Development (Belgium) and the National Fund for Scientific Research (Belgium).

\section{References}

1. Fuhrmann K, Reiher H, Semmler K, Glöckner E (1984) The effect of intensified conventional insulin therapy before and during pregnancy on the malformation rate in offspring of diabetic mothers. Exp Clin Endocrinol 83: 173177

2. Mills JL, Knopp RH, Simpson JL et al. (1988) Lack of relation of increased malformation rates in infants of diabetic mothers to glycemic control during organogenesis. N Engl J Med 318: 671-676

3. Elixhauser A, Weschler JM, Kitzmiller JL et al. (1993) Cost-benefit analysis of preconception care for women with established diabetes mellitus. Diabetes Care 16: 1146-1157

4. Pedersen JF, Molsted-Pedersen L (1981) Early fetal growth delay detected by ultrasound marks increased risk of congenital malformation in diabetic pregnancy. Br Med J 283: 269-271

5. Diamond MP, Moley KH, Pellicer A, Vaughn MK, De Cherney AH (1989) Effects of streptozotocin- and alloxan-incuced diabetes mellitus on mouse follicular and early embryo development. J Reprod Fert 86: 1-10

6. Moley KH, Vaughn WK, De Cherney. AH, Diamond MP (1991) Effect of diabetes mellitus on mouse preimplantation development. J Reprod Fert 93: 325-332

7. Vercheval M, De Hertogh R, Pampfer S et al. (1990) Experimental diabetes impairs rat embryo development during the preimplantation period. Diabetologia 33: 187-191

8. Pampfer S, De Hertogh R, Vanderheyden I, Michiels B, Vercheval M (1990) Decreased inner cell mass proportion in blastocysts from diabetic rats. Diabetes 39: 471-476

9. De Hertogh R, Vanderheyden I, Pampfer S, Robin D, Delcourt J (1992) Maternal insulin treatment improves preimplantation embryo development in diabetic rats. Diabetologia 35: 406-408

10. Ekka E, Vanderheyden I, De Hertogh R (1981) Oestrogen receptors and oestrogen-induced protein synthesis in the uterus of diabetic rats. Diabetologia 20: 578-582

11. Gates AH (1968) Rate of ovular development as a factor in embryonic survival. In: Rugh R (ed) The mouse, its reproduction and development. Burges Publishing, Minneapolis, pp 56-57

12. Pampfer S, Vanderheyden I, Michiels B, De Hertogh R (1990) Allocation of the inner cell mass and the trophecto- 
S. Pampfer et al.: In vitro growth of embryos from diabetic rats

derm cells in rat embryos during in vivo preimplantation development. Roux's Arch Dev Biol 198: 257-263

13. Armant DR, Kaplan HA, Lennarz WJ (1986) Fibronectin and laminin promote in vitro attachment and outgrowth of mouse blastocysts. Dev Biol 116: 519-523

14. Enders AC, Chavez DJ, Schlafke S (1981) Comparison of implantation in utero and in vitro. In: Glasser SR, Bullock DW (eds) Cellular and molecular aspects of implantation. Plenum Press, New York, pp 365-382

15. Lea R, Clark D (1993) Effects of decidual cell supernatants and lymphokines on murine trophoblast growth in vitro. Biol Reprod 48: 930-935

16. Heyner S, Rao LV, Jarett L, Smith RM (1989) Preimplantation mouse embryos internalize maternal insulin via receptor-mediated endocytosis: pattern of uptake and functional correlation. Dev Biol 134: 48-58

17. Barlow PW, Sherman MIS (1972) The biochemistry of differentiation of mouse trophoblast: studies on polyploidy. J Embryol Exp Morph 27: 447-465
18. Eriksson UJ, Dahlström E, Hellerström C (1983) Skeletal malformations in the offspring of diabetic rats after intermittent withdrawal of insulin in early gestation. Diabetes 32: 1141-1145

19. Eriksson RSM, Thunberg L, Eriksson UJ (1989) Effect of interrupted insulin treatment on fetal outcome of pregnant diabetic rats. Diabetes 38: 764-772

20. Dufrasnes E, Vanderheyden I, Robin D, Delcourt J, Pampfer S, De Hertogh R (1993) Glucose and pyruvate metabolism in preimplantation blastocysts from normal and diabetic rats. J Reprod Fert 98: 169-177

21. Roy S, Sala R, Cagliero E, Lorenzi M (1990) Overexpression of fibronectin induced by diabetes or high glucose: phenomenon with a memory. Proc Natl Acad Sci USA 87: 404-408

22. Pedersen RA (1988) Early mammalian embryogenesis. In: Knobil E, Neill J (eds) The physiology of reproduction. Raven Press, New York, pp 187-223

23. Ansell JD, Snow MHL (1975) The development of trophoblast in vitro from blastocysts containing varying amounts of inner cell mass. J Embryol Exp Morph 33: 177-185 